ring der functies in de industrie, riepen van zelf nieuwe organen in het leven. Zulk een is de systematische vorming van a rbeidskrachten, in het bijzonder die van bazen. Het doel van ile opleiding van bazen is de verhooging van hun bekwaamheid, opdat zij op de meest cconomische wijze de taak kunnen uitvoeren, die hun is opgedragen.

Om dit doel te bereiken, moet aan twee voorwaarden worden voldaan.

1. Fr moet een keus van de meest geschikten plaats vinden.

2. De gekozenen moeten doelmatig worden gevormd.

J) keus geschiedt:

a. door psychotechnische "Tests", teneinde de aangeboren kwaliteiten te leeren kennen.

b. door jarenlang hun werk, handelwijze en gedrag na te gaan.

De methode van opleiding is afhankelijk van plaatselijke on:standigheden en behoeften.

De ervaring leerde, dat het meeste succes werd behaald met zorgvuldig voorbereide speciale cursussen, die bestonden uit:

a. De bestudeering van goed gekozen leer-en handboeken.

b. Instructieve voordrachten met lichtbeelden, films en dergelijke hulpmiddelen.

c. Besprekingen en seminarie-oefeningen.

d. Uitwerking van aan de praktijk ontleende opgaven, huiswerk, enz.

De opleiding moet met proefmaken en ondervraging gepaard gaan en aan het eind van iederen cursus moet aan iederen deelnemer een getuigschrift worden nitgereikt over zijn bezoek en vor'deringen. Het is van het grootste belang, dat de beoordeeling in de hoogste mate objectief is.

De cursussen moeten, indien eenigszins mogelijk, door de leidende personen in de onderneming zelf worden gegeven. Slechts in die gevallen, dat in dien kring geen voldoend bekwame krachten aanwezig zijn, make men van deskundigen van buiten het bedrijf gebruik.

Wat de organisatie van het geheel betreft, deze worde toevertrouwd aan een speciaal orgaan - hetzij één persoon of een afdeeling.

P. Maillard, Frankrijk, diende een memorandum in, waarin de opleiding van bazen uitvoerig wordt besproken en een onderscheid wordt gemaakt tusschen de technische en sociale problemen, die zich daarbij voordoen. Bovenal legt hij nadruk op de noodzakelijkheid, om een geest van onderlinge samenwerking aan te kweeken. Mededeeling wordt gedaan van de resultaten, die met verschillende methoden werden bereikt. De schrijver besluit als volgt :

Van belang is het op te merken, dat zij, die bazen geworden zijn, gerecruteerd zijn uit de gewone arbeiders, vanwege hum bekwaamheid om leiding te geven in het werk. Want daaruit blijkt de mogelijkhcid niet slechts van een verdere technische ontwikkeling van den arbeider, doch bovenal, die van de ontwikkeling eener mentaliteit, waardoor de bazen de schakel tusschen de directie en de arbeiders kumnen zyjn. Daarvoor is slechts noodig, dat de leiders der industrie zich de noodige moeite geven en ook te dien opzichte toonen, dat zij hun taak begrijpen. Deze meening wordt ook door Amerikaansche en Engelsche ervaringen bevestigd. Daarom kan de schrijver zich niet vereenigen net Mr. Uruick, waar deze zegt van meening te zijn, dat alle pogingen om tot een rationale opleiding van bazen te komen, nog geen opvoedkundig systeem vormen, doch slechts lapwerk zijn om zoo goed mogelijk - d.i. hier met 5e rangs werk - de gevolgen te herstellen van verwaarloozing en kortzichtigheid bij de vroegere leiding.

Ongetwijfeld zijn de methoden onzer ambachtscholen (écoles techniques) voor de opleiding van bazen verouderd en beantwoorden grootendeels niet aan de eischen van onzen tijd; zij moeten bij het licht der ervaring worden verbeterd en haar grondbeginselen moeten worden vastgesteld, voor zoover dat $\log$ niet is geschied. Doch de door ons anngevoerde voorbeelden en gedaue waarnemingen, zegt de schrijver, bewijzen, dat het voor ben intelligente Directie, die opgewassen is tegen de moeilijkheden van haar taak, ieder oogenblik mogelijk is de geestesgesteldheid van haar personeel zoodanig te vormen, dat het zich vereenigt in betooning van trouw en groepsgeest.

De ,sleutelgroep" der bazen moet het voorwerp van de grootste zorg der Directie zın : de vele middelen, die door den schrijver zijn aangegeven, bieden gelegenheid een keus te doen bij het verhoogen van het moreele - en beroepsniveau van het corps der bazen, vóórdat men overgaat tot het tocpassen vall nieuwe methoden van wetenschappeljike bedrijfsor'ganisatie. Dan zal het niet een der minste redenen van rocm zyjn voor de rationalisatie, dat zij den stoot heeft gegeven tot een samenstemmen in gevoelens en pogingen van het geheele personeel: Directie, hoofd-en handarbeiders, tot hetzelfde doel : de dienst der gemeenschap.

C. V.

\section{HET NIEUWE BESTUURSEXAMEN VOOR DE VEREE- NIGDE FACULTEITEN DER RECHTSGELEERDHEID EN DER HANDELSWETENSCHAPPEN AAN DE UNIVERSITEIT VAN AMSTERDAM}

Bij Raadsbesluit van 20 Juli 1932 (Gemeenteblad 1932 afd. 3 volgn. 94) is, met wijziging van de Verordening tot regeling der Universiteit van Amsterdam, de gelegenheid geopend on aan die Universiteit een examen af te leggen, hetwelk den naam „Bestuursexamen” zal dragen. Aan dit examen, dat zal worden afgenomen door een commissie uit de vereenigde faculteiten der rechtsgeleerdheid en der handelswetenschappen, kumnen zich diegenen onderwerpen, die net gunstig gevolg het doctoraal examen in het Nederlandsch recht of in de handelswetenschappen hebben afgelegd, zoodat de studie voor het bestuursexamen beschouwd moet worden als een gespecialiseerde studie, gebaseerd op de volledige opleiding voor de zooeven genoemde doctoraal examens. Uit den aard der zaak worden ook meesters in de rechten en doctorandi in de handelswetenschappen, die de Universiteit reeds verlaten heben, tot het bestuursexamen toegelaten.

Aanleiding tot de instelling van dit examen was de in de practijk tot uiting gekomen wenschelijkheid, dat de besturen van openbare gemeenschappen als $\mathrm{Rijk}$, provincie en gemeente de beschikking verkrijgen over juristen, die meer economisch en administratiefrechtelijk georiënteerd zijn, en over doctorandi in de handelswetenschappen, die meer juridisch, in het bijzonder administraticfrechtelijk, onderlegd zijn dan door de opleiding voor het door hen afyelegd doctoraal examen wordt gewaalhorgd. Daarom omvat het bestuursexamen voor de meesters in de rechten als verplichte vakken: staathuishoudkunde, bedryfshuishoudkunde, administratiefrecht van Nederland en statistiek, met dien verstande, dat, wanneer staathuishoudkunde, bedrịfshuishoudkunde of statistiek deel hebben uitgemaakt van het doctoraal in de rechten, voor deze vakken vrijstelling wordt verleend. Als verplichte vakken voor de doctorandi in de handelswetenschappen noemt de nieuwe regeling: hoofdzaken van Nederlandsch staatsrecht, administratief recht van Nederland en 
hoofdzaken van strafrecht. Behalve in deze verplichte vakken wordt elke examinandus ondervraagd over een door hemzelf gekozen vak, als hoedanig de verordening noemt: sociologie, leer der financiën, arbeidsrecht en voor de meesters in rechten ook economische geschiedenis, en voorts eenig ander vak, door den examinandus onder goedkeuring der vereenigde faculteiten gekozen uit een der andere faculteiten, een en ander, voorzoover het vak niet reeds deel heeft uitgemaalit van het doctoraal examen.

De duur der studie voor het bestuursexamen mag worden gesteld op twee jaar. Het bureau der vereenigde faculteiten, bestaande uit Prof. Th. Limperg als voorzitter en Prof. Mr. $F$. J. A. II uart als secretaris, heeft thans zijn werkzaamheden aangevangen. Voor nadere inlichtingen over de bestuursoplciding kunnen belanghebbenden zich schriftelijk wenden tot den secretaris der vereenigde faculteiten (adres: Oudemanhuispoort 4, Amsterdam C.).

\section{REPERTORIUM VAN TIJDSCHRIFT-LITERATUUR OP HET GEBIED VAN ACCOUNTANCY EN BEDRIJFSHUISHOUDKUNDE}

Redactie: Mej. Dr. R. PHILIPS en Drs. G. L. GROENEVELD voor bedrijfseconomie en J. P. DE HAAN en J. C. SPANGENBERG voor accountancy

\section{A. ACCOUNTANCY}

\section{HET ACCOUNTANTSBEROEP}

De positie van den gemeente-acountant

L(e p p i n k, J. A.) - Schr, bespreekt een aantal vragen, die betreffende de positie van den gemeente-accountant reeds bestonden, dan wel door de herziening van de gemeentewet zijn gerezen.

A II 1

Financieel Overheidsbeheer 1 October 1932

De aansprakelijkheid van directeuren, commissarissen en accountant jegens de naamlooze vennootschap

Kat, Mr. O. B. W. de - Schr. gaat o.m. na, welke de wettelijke aansprakelijkheid is voor den "deskundige" van art. $42 \mathrm{a}$ ell $51 \mathrm{~b}$ W.v.K. A II 4 De Naaml. Vennootschap Oct. 1932

\section{Compulsory audit of corporations}

A ndre w s, F. B. - Verdedigt de wettelijk verplichte accountantscontrole, bij welke de voorschriften van de Federal Reserve Board van 1929 als leidraad genomen zouden kunnen worden. De Engelsche accountantsverklaring zou met een kleine wijziging ook voor Amerika kunnen dienen.

A II 4

The Journal of Accountancy Nov. 1932

\section{LEER VAN DE INIRICHTING}

Vergelijkend overzicht van het Powers en het Hollerith systeem

We erd, Ir. W. A. J. de - De bijzonderheden en de mogelijkheden van beide systemen worden uitvoerig uiteengezet.

A III 3

Administratieve Arbeid Oct. en Nov. 1932

\section{LEER VAN DE CONTROLE}

\section{Controle op de afwikkeling van faillissementen}

$\mathrm{N}$ ij s t, J. J. M. H. - Naar annleiding van de geruchtmakende fraude en verduistering, welke liebben plaats gehad bij de afwikkeling van het faillissement der Bossche Hansebank e.d., is dit artikel geschreven.

Behandeld wordt hoe de afwikkeling wettelijk is geregeld. Voorts wordt een pleidooi gehouden voor controle op deze afwikkeling.

A IV 3

\section{B. BEDRIJFSHUISHOUDKUNDE}

\section{a. ALGEMEENE BEDRIJFSHUISHOUDKUNDE}

\section{LEER VAN DEN KOSTPIRIJS EN DE PRIJSVORMING}

De electriciteitstarieven voor huishoudelijk verbruik in Nederlandsche steden met meer dan 100.000 inwoners

$\mathrm{V}$ is s e r, Dr. C. - Schr. publiceert dit artikel als het resultaat van onderzoek, in samenwerking met ir H. W. L. Brückman en C. A. Oudemans verricht. Als methode van onderzoek maakten zij gebruik van den z.g. typeverbruiker, waarvoor zij de tarieven berekenden. Het Amsterdamsche tarief blijkt het fijnst gedifferentieerd en geeft de beste aanpassing aan verbruiksmogelijkheden. Voorts heeft het Amsterdamsche tarief liet verbruik minder geschaad, resp. het sterkst bevorderd in vergelijking met het tarief van de andere gemeenten.

B a IV 9 Econ. Statistische Berichten 23 en 30 Nov. 1932

\section{LEER VAN DE FINANCIERING}

Rijk ...... en geen geld

Pola k, Prof. dr. N. J. - Schr. bepleit verzelfstandiging van het bedrijf voor den aanleg van wegen en bruggen, hetzij door concessies, hetzij door verzelfstandiging van het Wegenfonds, teneinde de financiering en versnelling van wegen- en bruggenbouw te bevorderen.

B a V 5a Econ. Statistische Berichten 19 Oct. 1932

Working capital in public-utility regulation

P a to n, W. A. - Besproken worden eenige hiermede verbandhoudende vraagstukken.

$\mathrm{B}$ a $\mathrm{V} 7$

The Journal of Accountancy October 1932

\section{LEER VAN DE ORGANISATIE}

De wet der verminderende meeropbrengsten ten opzichte van het kapitaal

Ge ne chten, dr. R. va $n$ - De toevoeging van de eerste kapitaaldeeltjes geven een meer dan evenredige vergrooting van het resultaat, bij verdere vermeerdering van kapitaal wordt de toename steeds geringer. De wet heeft verschillende gevolgen voorzooverre zij geld ten opzichte van den grond en den arbeid eenerzijds en voor het kapitaal anderzijds.

B a Vl 1

De Economist Sept. 1932

Doelmatige bedrijfsorganisatie in een machinefabriek

Velden, ir. C. N. van der-Er wordt een analyse van een machinebedrijf gegeven, vervolgens de hoofdregels voor elk van de onderdeelen, dan regels voor het formuliersysteem en daarna voorbeelden van toepassing. Het geheel is een overzichtelijk voorbeeld van moderne bedrijfsorganisatie.

B a VI 13 Polytechnisch Weekblad 22 Sept. 1932 p. 597-603

Le "Comment" d'une organisation

$\mathrm{H}$ ij $\mathrm{m}$ a n s, E. en J. Renten a a $\mathrm{R}$. - Schr. behandelen de reorganisatie van een industrieele onderneming.

B a VI 13

L'Organisation October 1932

De maandcijfers der begrooting

G r o e n e veld, drs. G. L. - Toepassing van seizoenindices als onderdeel van bıdget-contrôle van bedrijfsopbrengsten.

B a VI 18

P. T. T. Nieuws Nov. 1932

L'éclairage des bureaux et des intérieurs de magasins

B I u m e $n$ t li a l, L. - De sterkte der verlichting hangt mede af van de bestemming van een lokaal. Verschillende belichtingen worden beschreven.

B a VI 19

L'Organisation October 1932

Modernisation of the office

$\mathrm{D}$ e s b o r o u g ll, W. - Bij de moderniseering van de kantoorarbeid dient men zeer systematisch te werk te gaan, wil deze haar maximumrendement opleveren.

B a VI 23

The Accountants' Journal October 1932

\section{LEER VAN DE ARBEIDSVOORWAARDEN}

Arbeidsspreiding en loon

G a l e n, Mr. J. va n - Schr. trekt op grond van verschillende argumenten te velde tegen de idee van de 40-urige werkweek en bepleit op grond van de wet Rueff (reduceering van werkloosheid 